out Britain, completed questionnaires will be sent directly to a coordinator at the Royal College of Physicians, who will remove all identification before transmitting the data to the inquiry team for analysis. After the anonymous data have been extracted the records will be destroyed. As with the inquiries into maternal and perioperative deaths, the Department of Health has confirmed that it supports the total confidentiality of documents prepared for the inquiry. In practice this means that in any court case the court would weigh the public interest in preserving confidentiality in any judgment about disclosure. The inquiry will depend for its success on the cooperation of clinicians, who will take part only if they are convinced that it is both confidential and noncensorious. The steering committee has taken great pains to ensure that is so.

Chairman of Steering Committee,

Department of Medical Genetics,

St Mary's Hospital,

Manchester M13 0JH

RODNEY HARRIS

Royal College of Physicians of London. Purchasers' guidelines to genetic services in the NHS. An aid to assessing the genetic services required by the resident population of an average health district. London: Royal College of Physicians, 1991.

2 Baird PA, Anderson TW, Newcombe HB, Lowry RB. Genetic disorders on children and young adults: a population study. Am $\mathcal{F}$ Hum Genet 1988;42:677-9.

\title{
Adults with congenital heart disease
}

\section{A comprehensive specialist service is needed}

Over the past 50 years advances in medical treatment and surgical procedures have radically altered the outlook for children with congenital heart disease. In the 1950s only $10-15 \%$ of infants with known congenital heart disease survived until puberty, ${ }^{1}$ whereas now many survive childhood. This success story has resulted in a growing population of adolescents and young adults with congenital heart disease, an increasing proportion of whom have complex cardiovascular abnormalities. In the United States well over 500000 such patients have reached adulthood in the past 30 years. ${ }^{2}$ Currently patients who outgrow the paediatric clinic are either lost to follow up or managed as "one off" cases by adult physicians who are more experienced in acquired than congenital heart disease. Specialised centres for this new category of patients are therefore essential to optimise care and to collect follow up data to provide rational advice about lifestyle and future prognosis.

A major requirement for these patients when they grow to adolescence and young adulthood is a facility for excellent cardiac surgery. Many of the patients will have had surgery in childhood, but total correction is rare. ${ }^{3}$ Most will therefore need long term medical surveillance, and many need reoperation for replacement of bioprosthetic valves or extracardiac conduits inserted in childhood. Further indications for reoperation include residual defects after definitive repair, and staged surgery for complex defects, such as pulmonary atresia with ventricular septal defect. Reoperation is difficult and carries a high risk, ${ }^{4}$ particularly if undertaken by surgeons inexperienced in such problems. Other adults may require their first operation for lesions that were well tolerated during childhood, such as bicuspid aortic valve or Ebstein's anomaly. Finally, despite the best efforts at repair, an increasing number of these patients will eventually become candidates for heart or heart-lung transplantation. They need considerable medical, social, and psychological support.

Arrhythmia is the commonest medical problem encountered in this population. Loss of sinus rhythm and supraventricular tachyarrhythmia are seen with increasing frequency during follow up after intra-atrial repair for transposition of the great arteries (Mustard or Senning procedure) and after the Fontan operation. ${ }^{5}$ Awareness of these late complications has contributed to a change in the preferred initial surgery for transposition and a revision in technique for the Fontan procedure. ${ }^{6}$ Ventricular tachyarrhythmia is often observed during ambulatory electrocardiographic monitoring in asymptomatic survivors after repair of tetralogy of Fallot. ${ }^{7}$ The risk associated with $\vec{A}$ arrhythmia and the need for treatment depend on the $\vec{\omega}$ underlying haemodynamic condition, so the physician decid- $O$ ing on antiarrhythmic treatment and the need for pacing needs both electrophysiological skill and an understanding of ${ }_{0}$ the congenital heart defect itself. The haemodynamic state $\underset{\varnothing}{\mathbb{D}}$ may be especially vulnerable to either the arrhythmia or the 3 myocardial depressant effects of antiarrythmic treatment $\stackrel{\mathbb{D}}{-}$ when a right ventricle supplies the systemic circulation after $\vec{\bullet}$

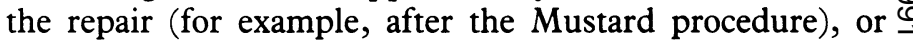
when only one ventricle is functioning (for example, in the Fontan circulation).

Patients with cyanotic congenital heart disease, particularly those with pulmonary vascular disease (Eisenmenger's syndrome), require special care. Erythrocytosis invariably occurs $\stackrel{\mathbb{Q}}{\mathscr{Q}}$ and in some may cause hyperviscosity symptoms such as $\overrightarrow{\vec{B}}$ headache or fatigue. Injudicious phlebotomy may aggravate 3 symptoms by producing iron deficiency. ${ }^{8}$ Stroke is rare in these young adults, but bleeding problems occur (due to defective haemostasis) and renal insufficiency and arthropathy (due to hyperuricaemia) are common complicating features. ${ }^{9}$ Patients with Eisenmenger's syndrome are at particular risk during anaesthesia, exercise, and pregnancy. This is clearly one condition in which counselling against pregnancy is appropriate. In other adults with congenital heart disease considering pregnancy counselling is necessary to explain the potential risks to both mother and fetus. ${ }^{11}{ }^{11} \mathrm{~N}$

The most recent confidential enquiry into maternal deaths $\frac{D}{0}$ reported an increase in deaths due to cardiac disease, attributed to deaths in women who had previously had $\widetilde{N}$ surgery for congenital heart lesions. ${ }^{12}$ This emphasises the $\omega$ need for expert attention from obstetricians, cardiologists, and anaesthetists for this group of patients.

Endocarditis is a risk for all patients with congenital heart $\stackrel{\Phi}{\mathcal{D}}$ disease, particularly adolescents, who often do not comply 0 with antibiotic prophylaxis. This is perhaps the main reason for following up patients with simple lesions of minor $\stackrel{\mathbb{D}}{\mathscr{D}}$ haemodynamic importance, such as those with a small $\stackrel{\mathbb{Q}}{\varrho}$ ventricular septal defect. Any such patient who is unwell with fever may have cardiac infection and should have blood cultures done before empirical antibiotic treatment is prescribed.

Psychosocial problems are also important. Many of the "normal" ordeals of adolescence may be more difficult for this group, in whom chronic illness, embarrassing scars, and excessive limitation of activities may inhibit normal social 
intercourse and maturation. Advice is often sought on participation in exercise, ${ }^{13}$ sexual activity, contraception, employment, and insurance. In many cases too few data are available to allow informed decisions. In a recent survey we found that prospective employers and insurers were often extremely cautious about applicants with congenital heart disease because of a perceived risk of premature incapacity and death. In some cases this caution is appropriate, but in people without symptoms or residual abnormalities this approach is unnecessarily harsh. One of the major roles of a specialised cardiac service for young adults would be to define the functional capability and long term survival of patients with congenital heart disease.

To care adequately for adults with congenital heart defects a specialised service must be available for referral or consultation. Efforts are being made to determine the provision available in Europe and to organise care. ${ }^{1+}$ The service must be able to deal with both the cardiac problems and the wide range of other medical problems that occur in these patients, to provide expert surgery, and to offer psychosocial support and advice. Concentrating on this group of patients will provide education and opportunities for research for a new specialist group of cardiologists, surgeons, and health professionals. Long term follow up data from such clinics would allow services to be planned and also enable paediatric cardiologists to modify early management to optimise later outcome. With a high level of medical care and psychosocial advice each adult with congenital heart disease would have the best chance of achieving his or her full potential.

DAVID S CELERMAJER Honorary Senior Registrar JOHN E DEANFIELD

Cardiothoracic Unit, Consultant Cardiologist

Hospital for Sick Children,

Great Ormond Street,

London WCIN 3JH

MacMahon B, McKeown T, Record RG. The incidence and life expectation of children with

congenital heart disease. $B r$ Heart $\mathcal{f}$ 1953;15:121-9.
Perloff JK. Congenital heart disease in adults. In: Kelly WN, ed. Textbook of internal medicine. Philadelphia: Lippincott, 1989:223-35.

Stark J. Do we really correct congenital heart defects? 7 Thorac Cardiovasc Surg 1989:97:1-9.

4 Stark J, Pacifico AD. Reoperations in cardiac surgery. London: Springer-Verlag, 1989.

Deanfield JE Camm J, McCartney FJ, Cartwright T, Douglas J Drew J et al Arhy haia a d

Deanfield JE, Camm J, McCartney FJ, Cartwright T, Douglas J, Drew J, et al. Arrhythmia and late mortality after Mustard and Senning operation for transposition of the great arteries: an eighes year prospective study. I Thorac Cardiovasc Surg 1988;96:569-76.

6 De Leval MR, Kilner P, Gewillig M, Bull C. Total cavopulmonary connection: a logical alternative to atriopulmonary connection for complex Fontan operations. I Thorac Cardiovasc Surg1988;96:682-95.

Deanfield JE. Late ventricular arrhythmias occurring after repair of tetralogy of Fallot: do the matter? Int $\mathcal{F}$ Cardiol 1991;30:143-50.

8 Perloff JK, Rosove MH, Child JS, Wright GB. Adults with cyanotic congenital heart disease

haematologic management. Ann Intern Med 1988;109:406-13.
9 Territo MC, Rosove MH, Perloff JK. Cyanotic congenital heart disease. In: Perloff JK, Child JS W eds. Congenital heart disease in adults. Philadelphia: WB Saunders, 1991:93-103.

$10 \mathrm{De}$ Swiet $\mathrm{M}$. Management of congenital heart disease in pregnancy. In: Anderson RH, Macartne FJ, Shinebourne EA, Tynan M, eds. Paediatric cardiology. Edinburgh: Churchill Livingstone FJ, Shinebourne EA, Tynan M, eds. Paediatric cardiology. Edinburgh: Churchill Livingstone,

11 Nora JJ. McGill CW, McNamara DG. Recurrence risks in common and uncommon congenital heart lesions. Teratology 1970;3:325-30.

12 Report on Confidential Enquiries into Maternal Deaths in the United Kingdom 1985-87. London $\overrightarrow{\vec{C}}$

13 Cullen S, Celermajer DS, Deanfield JE. Exercise in congenital heart disease. Cardiology in the young 1991;1:129-35

14 Somerville J. Congenital heart disease in the adolescent. Arch Dis Child 1989;64:771-3.

\section{Understanding Marfan's syndrome}

\section{Abraham Lincoln revisited}

The retrospective diagnosis of rare and exotic diseases in celebrities from the past has provided a rich source of speculation for medical historians, who must have often lamented their inability to call on contemporary medical evidence. High on the list of putative diagnoses comes Marfan's syndrome: Abraham Lincoln, Paganini, and Rachmaninov may have had it.' Events of the past few months suggest that for Marfan's syndrome, and possibly other single gene disorders, the medical historian may soon be able to call on the molecular biologist as an expert witness.

Even the most inattentive medical student is usually familiar with Marfan's syndrome. Although relatively rare, with an estimated prevalence of 1 in 10000 , the full blown clinical picture of tall stature, long limbs, and arachnodactyly is well known. A firm diagnosis should be based on well defined diagnostic criteria ${ }^{2}$ with involvement of at least two and preferably all three of the major systems affected - that is, the eye, heart, and skeleton. To these can be added a fourth diagnostic criterion, a positive family history - for it has long been recognised that Marfan's syndrome shows autosomal dominant inheritance with close to complete penetrance (that is, everyone with the gene manifests it to some degree) but very variable expression even among affected members of the same family.

Despite extensive research, progress on the genetic front was disappointingly sluggish during a decade that witnessed remarkable progress in the understanding of most common single gene disorders. Then quite suddenly the situation changed dramatically with the almost simultaneous announcements that fibrillin, a component of the microfibrillar system associated with elastin, was lacking in skin from patients with Marfan's syndrome ${ }^{3}$ and that the disease cosegregated with polymorphic DNA markers on chromo some $15 \mathrm{q} .{ }^{+}$The attractive unifying hypothesis that the genet for fibrillin would be located on chromosome $15 \mathrm{q}$ proved to be valid. Further support for fibrillin as the basic defect has come from two further studies. One has confirmed tight linkage of $\vec{P}$. polymorphisms in the fibrillin gene with the disease in multiplex families ${ }^{5}$; the other has found an identical arginin to proline point mutation in two unrelated patients. ${ }^{6}$

In most genetic disorders the molecular story has proved more complex than expected, with allelic (different mutation $\oint$ at the same locus) and locus heterogeneity (mutations at different loci) proving the rule rather than the exception? Marfan's syndrome will probably be no different, a poins amply illustrated by the finding of the original arginine to proline mutation in only two of over 40 patients. ${ }^{6}$ Locus heterogeneity seems less likely given the very recent demon stration of linkage to chromosome $15 q$ in 17 families from five different populations drawn from Europe and the Unite States. ${ }^{7}$ Healthy scepticism, however, is in order until a muct larger volume of data has been accumulated.

What, if any, are the practical benefits of these observations for patients and their doctors? In the short term these will b] diagnostic rather than therapeutic, although the two canno be totally separated. In a family with more than one affecte $\bar{\phi}$ member, in which linkage to chromosome $15 \mathrm{q}$ has bee shown, reliable preclinical and, if acceptable, prenatal diag nosis will now be available. Inevitably this will raise difficu野 issues at a time when the ethical aspects of presymptomatic diagnosis in children ${ }^{8}$ and associated problems of insurance are under active discussion. Given the potential for cardiac morbidity and mortality in young adults with Marfan's syndrome, ${ }^{10}$ the case for early diagnosis will be 